\title{
EL GÉNERO EN LAS EXPERIENCIAS DE VIOLENCIA DE MUJERES DE SAN CRIS- TÓBAL DE LAS CASAS, CHIAPAS
}

\author{
GENDER IN THE EXPERIENCES OF \\ VIOLENCE AGAINST WOMEN IN SAN \\ CRISTÓBAL DE LAS CASAS, CHIAPAS \\ MARIANA RUÍZ GÓMEZ1 \\ JUAN IVÁN MARTÍNEZ ORTEGA
}

\footnotetext{
${ }^{1}$ Universidad Autónoma de Chiapas. Correo

electrónico: mariarugoz@gmail.com

${ }^{2}$ El Colegio de la Frontera Sur. Correo electrónico:

jimartinez@ecosur.mx
}

\begin{abstract}
Resumen
Diversos estudios indican que la violencia contra las mujeres en San Cristóbal de Las Casas, Chiapas, representa una problemática social de grandes dimensiones, en ellos se da cuenta del panorama en su conjunto, pero se pasan por alto las especificidades de las experiencias de las mujeres incluidas en la generalidad de un dato. Además de cuantificar, es importante estudiar la violencia contra las mujeres desde la mirada de ellas mismas, analizar cómo la viven a partir de sus sentires y pensamientos, por ello, en este artículo se pretende responder la siguiente pregunta de investigación: ¿cómo experimentan la violencia las mujeres que la han padecido
\end{abstract}


en algún momento de su vida? concretamente las mujeres jóvenes y adultas del municipio citado. El estudio se enmarca en la investigación cualitativa y en la antropología de género, el concepto central que se utiliza es el de la experiencia vivida como experiencia de género. Se definió una muestra no probabilística de tipo intencional, por lo que se realizaron entrevistas semiestructuradas a 14 mujeres de diferentes perfiles sociodemográficos radicadas en el municipio; los tópicos establecidos en el guion conformaron árboles de categorías cuyo contenido fue codificado y analizado con la ayuda del software de análisis cualitativo Nvivo. Los resultados indican que las experiencias de violencia de las mujeres están atravesadas por la situación vital y por la condición de género. Las entrevistadas experimentaron en momentos clave de su vida, de formas violentas, lo que significa ser mujer; en cada una de esas etapas, aprendieron y aprehendieron cooperando o por medios violentos lo que se espera de ellas, cómo debe ser una niña, una jovencita decente, una buena madre y una buena esposa, y cómo es que no deben ejercer su sexualidad.

Palabras clave: experiencia de género, violencia de género, violencia contra las mujeres, investigación feminista, antropología de género 


\section{Abstract}

Several studies indicate that violence against women in San Cristóbal de Las Casas, Chiapas, represents a social problem of great dimensions, in which the landscape a whole is taken into account but the specificities of the experiences of women included in it are ignored in the general data. Asides from quantifying, it is important to study violence against women from the perspective of themselves, analyze how they live, their feelings and thoughts, therefore, this article aims to answer the following research question: How do women experience violence when they have suffered it at some point in their life? specifically the young and adult women of the municipality aforementioned. The study is a qualitative research in the frame of gender anthropology, the central concept that is used is the lived experience as a gender experience. A non-probabilistic sample of intentional type was defined, consequently, semi-structured interviews were carried out with 14 women of different socio-demographic profiles located in the municipality; the topics established in the script formed trees of categories whose content was codified and analyzed with the help of the qualitative analysis software Nvivo. The results indicate that the experiences of violence of women are crossed by the vital situation and the condition of gender, the interviewees experienced in key moments of their life, in violent ways, what it means to be a woman, in each one of 
those stages, they learned and apprehended by cooperating or by violent means what is expected of them and how it must be a girl, a decent young girl, a good mother and a good wife and how they should not exercise their sexuality.

Keywords: gender experience, gender violence, violence against women, feminist research, gender anthropology

RECEPCIÓN: 18 DE JULIO DE 2018/ACEPTACIÓN: 23 DE FEBRERO DE 2019

\section{INTRODUCCIÓN}

San Cristóbal de Las Casas es uno de los 122 municipios que conforman el Estado de Chiapas, es el cuarto municipio más poblado de la entidad; cifras oficiales indican que en 2015 la población del municipio asciende a 209,591 personas, de las cuales 111,383 son mujeres. Se estima para ese año que el $30.9 \%$ de los hogares del municipio cuentan con jefatura femenina, lo cual lo coloca en el noveno lugar de los municipios chiapanecos en ese rubro. La población de 3 años y más que habla alguna lengua indígena asciende a 63,454 personas, de las cuales 34,305 son mujeres (INEGI, 2016).

Con relación al tema de la violencia contra las mujeres, de acuerdo con los datos levantados en 2016 por la Encuesta Nacional sobre la Dinámica de las Relaciones en los Hogares 
(ENDIREH), Chiapas es el Estado con menor prevalencia de violencia contra la mujer del país con $52.4 \%$; el otro extremo es la Ciudad de México, lugar en el que el $79.8 \%$ de las mujeres de 15 años y más manifestaron haber enfrentado al menos un incidente de algún tipo de violencia (INEGI, 2017). Esta posición de Chiapas a nivel nacional, contrasta con lo documentado y denunciado por Organizaciones de la Sociedad Civil (OSCs); solo en materia de feminicidios, el Observatorio Feminista contra la Violencia a las Mujeres de Chiapas (OFVMCH, 2018), indica que en diciembre de 2017 ocurrieron 23 muertes violentas contra mujeres, 25 en noviembre, 13 en octubre, 17 en septiembre y 20 en agosto; eso es tres veces más que la fuente oficial que, en este caso, es el Secretariado Ejecutivo del Sistema Nacional de Seguridad Pública (SESNSP, 2018).

La ENDIREH no presenta información desagregada a nivel municipal, por ello, en el caso de San Cristóbal de Las Casas, la información disponible no tiene un grado de especificidad como a nivel nacional y estatal; no obstante, organizaciones civiles han documentado la violencia que padecen las mujeres en el municipio. En un sondeo realizado en el año 2004 por el Colectivo Feminista Mercedes Olivera y Bustamante A. C. (COFEMO), encuestaron a 380 mujeres con edades de 15 a 45 años, de las cuales 148 reportan alguna forma de violencia, se indica que el número de mujeres agredidas se triplicó en el periodo 2000-2004. De ellas, el 57.6\% tenían entre 15 y 25 años y el $21.4 \%$ entre 25 y 35 años, de las 380 mujeres 
encuestadas 9 fueron violadas y 11 experimentaron intento de violación, además, el $70 \%$ sufrió agresiones tales como hostigamiento verbal, manoseo y persecución (COFEMO A. C., 2016).

Otro estudio también da cuenta de altos índices de violencia contra las mujeres en dos de los barrios considerados de mayor importancia en el municipio. Dicho estudio es un análisis cuantitativo en el que se documenta que en los Barrios de María Auxiliadora y Santa Lucía, el $70.1 \%$ de las mujeres encuestadas han padecido algún tipo de violencia al menos una vez en su vida y $63.2 \%$ en el año previo a la encuesta; sobre este último dato, el $54.7 \%$ de las mujeres encuestadas manifestaron haber experimentado violencia psicológica, 29.9\% física, $26.5 \%$ sexual y $36.8 \%$ económica (Morales, Sánchez y Zúñiga, 2008).

Los datos y estudios referidos líneas arriba, indican que la violencia contra las mujeres en este municipio representa una problemática social de grandes dimensiones. Los estudios citados dan cuenta del panorama en su conjunto, pero pasan por alto las especificidades de las experiencias de cada una de las mujeres que son incluidas en la generalidad de un dato. Además de cuantificar, es importante estudiar la violencia contra las mujeres desde la mirada de ellas mismas, y analizar cómo la viven a partir de sus sentires y pensamientos, por ello, resultó pertinente realizar la siguiente pregunta de investigación: ¿Cómo experimentan la violencia las mujeres que la han 
padecido en algún momento de su vida?, específicamente las mujeres jóvenes y adultas entrevistadas de San Cristóbal de Las Casas, Chiapas.

Para responder a la pregunta, la estructura del artículo está integrada por cuatro apartados, además de la introducción y las consideraciones finales. En el primero y segundo, se realiza una aproximación conceptual al género, la violencia de género contra las mujeres y la experiencia de género; en el tercero, se presenta la estrategia metodológica utilizada; y el cuarto, son los resultados obtenidos respecto a cómo experimentan las mujeres de San Cristóbal de Las Casas la violencia que se ejerce sobre ellas, a éste lo conforman cuatro incisos, tres correspondientes a las etapas vitales de las mujeres y uno referente a la situación y condición de género.

\section{GÉNERO Y VIOLENCIA DE GÉNERO CONTRA LAS MUJERES}

Marta Lamas (1996) distingue al género como asignación, rol, identidad y categoría; adicionalmente podemos incluir la teoría, la perspectiva y el sistema sexogénero, este último es definido como "el conjunto de disposiciones por el que una sociedad transforma la sexualidad biológica en productos de la actividad humana, y en el cual se satisfacen esas necesidades humanas transformadas" (Rubin, 1986, p. 97). Es decir, son los procesos, prácticas y acciones me- 
diante las cuales determinados grupos sociales dan un significado cultural a un hecho biológico, esto es, convierten al sexo en género.

Respecto al género como categoría, Joan Wallach Scott identifica cuatro elementos interrelacionados: lo simbólico, lo normativo, lo institucional y lo subjetivo. Podemos utilizar el género para analizar en determinadas sociedades cómo se simboliza lo femenino y lo masculino, los mitos y las representaciones, entre otras; en lo normativo se pueden estudiar las doctrinas religiosas, educativas, legales o políticas, y el significado que en ellas tiene el género; en lo institucional, ubica a la familia, el mercado de trabajo y también las instituciones educativas y políticas, y finalmente, lo subjetivo lo relaciona con las formas en que se construyen las identidades genéricas (Scott, 1996, pp. 287-289).

Utilizar el género como categoría de análisis conduce a aplicar la perspectiva de género en la investigación, dotando a esta de un posicionamiento, pues lleva implícito un compromiso y una definición política; implica estar en contra de la desigualdad, la violencia y la opresión de género, "...es una denuncia de sus daños y su destrucción y es, a la vez, un conjunto de acciones y alternativas para erradicarlas" (Lagarde, 1996a, p. 33).

De tal suerte que, desde esa posición, se puede analizar la violencia de género. Uno de los antecedentes institucionales de dicho término es la Declaración sobre la eliminación de la 
violencia contra la mujer que indica: "A los efectos de la presente Declaración, por 'violencia contra la mujer' se entiende todo acto de violencia basado en la pertenencia al sexo femenino que tenga o pueda tener como resultado un daño o sufrimiento físico, sexual o psicológico para la mujer..." (ONU, 1993).

Un año más tarde, en 1994, la Organización de Estados Americanos (OEA) firmó la Convención Interamericana para Prevenir, Sancionar y Erradicar la Violencia contra la Mujer "Convención de Belém do Pará", que en su artículo 1 establece: "debe entenderse por violencia contra la mujer cualquier acción o conducta, basada en su género, que cause muerte, daño o sufrimiento físico, sexual o psicológico a la mujer, tanto en el ámbito público como en el privado" (OEA, 1994).

En 1995 se llevó a cabo La Cuarta Conferencia Mundial sobre la Mujer, en Beijing, China; en el Informe en español de la misma ya se planteaban con claridad los términos igualdad de género, violencia basada en el género y perspectiva de género (ONU, 1996). Como puede apreciarse, un origen de las concepciones de violencia contra las mujeres como violencia de género es institucional, pero no por ello es ajeno o contrario a las demandas de algunos sectores del feminismo, por el contrario, puede considerarse una materialización de una de sus demandas que es la relativa a eliminar la violencia contra las mujeres.

Dado que existe diversidad de formas para denominar el fenómeno, en este texto se opta por el término violencia de gé- 
nero en contra de las mujeres. Con esta denominación se "resalta la importancia de la diferencia de género en el conjunto de factores sexuales, sociales, económicos, jurídicos, políticos y culturales que determinan los patrones de dominación estructural de los hombres sobre las mujeres" (Lagarde, 2005, pp. 15-16 en Muñoz, 2011, p. 18). Es decir, al mencionar solo violencia contra las mujeres se invisibiliza el hecho de que son motivaciones de género las que generan la violencia; y con el término violencia de género se invisibiliza que mayoritariamente son mujeres las que padecen este tipo de violencia; entonces la propuesta de Lagarde resulta ser la más atinada.

No obstante, en México, la Ley General de Acceso a las Mujeres a una Vida Libre de Violencia, impulsada por la propia Marcela Lagarde, retoma el término Violencia contra las mujeres, pero en su definición sí se precisan las motivaciones de género, de ahí que en esa ley se defina de la siguiente manera: "Cualquier acción u omisión, basada en su género, que les cause daño o sufrimiento psicológico, físico, patrimonial, económico, sexual o la muerte tanto en el ámbito privado como en el público" (DOF, 2007). Dicha Ley distingue entre violencia física, patrimonial, económica, sexual y cualesquiera otras formas que dañen la integridad, la dignidad y la libertad de las mujeres; también refiere a distintos ámbitos de la violencia que pueden ser el familiar, laboral o docente, adicionalmente, considera la violencia en la comunidad, institucional y feminicida. 
Los tipos y los ámbitos de la violencia están atravesados por el dominio, sometimiento y abuso que se ejerce sobre la vida de las mujeres; actos concretos de violencia de género pueden ser: amenazas, chantajes, golpes físicos y agresiones con objetos o armas, acciones que degraden o dañen el libre ejercicio de su sexualidad, retención o sustracción de documentos personales, bienes materiales o económicos de la persona, y el control que se ejerce sobre ellas, sus cuerpos, sus tiempos, sus decisiones, sus actividades, sus ingresos, su trabajo, etcétera.

\section{LA EXPERIENCIA VIVIDA COMO EXPERIENCIA DE GÉNERO}

La segunda tesis de El Segundo sexo de la filósofa francesa Simone de Beauvoir (1981), es un referente para el feminismo y los estudios de género, "no se nace mujer: se llega a serlo", es planteado desde la Antropología como la construcción cultural de la diferencia sexual (Lamas, 1996). El segundo volumen de la obra, denominado La experiencia vivida, analiza cómo experimentan las mujeres la infancia, la juventud, la iniciación sexual y el ser lesbiana, también discute la situación de la mujer casada, la madre, la vida social, la prostitución y la vejez. La antropología de la experiencia, rescata la idea de la experiencia vivida en relación con lo común y lo general, tal disciplina "defiende que una obra, 
acción, vivencia o expresión son totalidades singulares, no deducibles de lo común, pero elaboradas a partir de lo común, y cuya comprensión ha de partir de ello" (Díaz, 1997, p. 6).

En comunión con ello, la antropología de género distingue entre situación y condición, "Las mujeres comparten como género la misma condición histórica, pero difieren en cuanto a sus situaciones de vida y en los grados y niveles de la opresión" (Lagarde, 2005, p. 34), es decir, la situación alude a la existencia concreta de mujeres particulares, singulares como su lengua, religión, edad, orientación sexual y nacionalidad, mientras que la condición se refiere a una creación histórica compartida por las mujeres en su conjunto o lo común: "La condición genérica de las mujeres está estructurada en torno a dos ejes fundamentales: la sexualidad escindida de las mujeres, y la definición de las mujeres en relación con el poder-como afirmación o como sujeción-, y con los otros" (Lagarde, 2005, p. 35).

En el caso que nos ocupa, como se verá más adelante, las mujeres entrevistadas tienen especificidades propias de su situación vital, pero también se identificaron elementos que comparten como género femenino. Ambas, situación y condición, atraviesan la experiencia vivida de las mujeres que padecen violencia. Para identificar tales aspectos, resulta pertinente recurrir a la propuesta de Simone de Beauvoir, quien sostiene que la mujer se hace a partir de experimentar, en calidad de 
otro, momentos clave en la infancia, juventud, iniciación sexual, el matrimonio, la maternidad, entre otros; pues es en la vivencia de esas experiencias que se configura un supuesto destino tradicional de la mujer, por lo que es importante conocer cómo es para las mujeres el aprendizaje de esa condición, qué evasiones están permitidas y cuáles no (Beauvoir, 1981).

La teórica feminista, Teresa de Lauretis, refiere a la experiencia como un entramado de significados, hábitos, disposiciones, asociaciones y percepciones que son producidos por la interacción de la persona con el mundo externo (Lauretis, 1994). Esta experiencia, según la autora, cambia continuamente para cada sujeto por su forma de relacionarse con la realidad social, en la cual están incluidas las relaciones sociales de género. Cada persona experimenta y se relaciona de manera distinta con el mundo, un mismo hecho o acontecimiento puede significar y percibirse de diferente forma en cada sujeto, pero esos significados dados a lo vivido, están atravesados por nuestra construcción genérica, las relaciones de género marcan nuestra experiencia.

Así entonces, tenemos que la experiencia de género refiere a "los efectos de significado y las autorepresentaciones producidas en el sujeto por las prácticas socioculturales, los discursos y las instituciones dedicadas a la producción de mujeres y varones" (Lauretis, 1994, p. 227). La asignación, el rol y la identidad de género originan que las experiencias de vida estén generizadas; al nacer, a partir del sexo se asigna un géne- 
ro, pero también se comienza a experimentar el mundo a partir de esa asignación, la experiencia femenina está ligada al sexo y la sexualidad de las mujeres. Un mismo hecho, como perder la virginidad, por ejemplo, es experimentado y valorado socialmente de manera desigual, dependiendo del sexo y el género de la persona. Instituciones como la familia, la iglesia y el Estado son claves en esas experiencias, pues producen y reproducen un mundo dividido en lo masculino y lo femenino.

\section{ESTRATEGIA METODOLÓGICA}

El estudio utiliza una metodología cualitativa, pues

trata de conocer el conjunto de atributos interrelacionados que caracterizan al hecho social (Valles, 1997). El abordaje se realiza desde la antropología de género, por lo que da cuenta de expresiones sociales en razón de género y de los modelos de estratificación y jerarquización que subyacen al sistema sexo-género (Martín, 2008). Dado que se trata de un tema sensible que cuando se vive, es difícil externar, resultó complicado cumplir con elementos de la etnografía tradicional, por ejemplo, trasladarse al lugar de los hechos, realizar estancias prolongadas en el terreno o hacer observación participante cuando ocurre la violencia. No obstante, sí se tomaron en cuenta elementos de la etnografía feminista, es decir, se consideró a las mujeres como sujeto privilegiado de la investi- 
gación, se propuso mostrar sensibilidad a la experiencia de las mujeres y se asumió un carácter político al posicionarse contra la opresión. A decir de Martha Castañeda (2012), en dicho tipo de investigación se requiere observar, describir e interpretar para visibilizar, desnaturalizar e historizar las desigualdades, develar cómo las mujeres se perciben a sí mismas, por ello se les da la voz y se les reconoce como emisoras de discursos válidos, además, pone atención en la situación y condición de género de las sujetos.

La técnica de investigación que se consideró más acorde a las características del tema y de las sujetos, fue la entrevista semi-estructurada, la cual en su diseño incluyó una guía para respuestas abiertas y con la flexibilidad de enfatizar en algún tema emergente que la guía original no contemplara (Sautu, 2005). También se realizaron notas de campo en cada una de las visitas realizadas a las mujeres estudiadas, siguiendo a Doris Lamus (2015), quien recomienda no confiar en la memoria y atender al comportamiento no verbal y contextualizar el registro de la información, entre otras.

Para definir a las sujetos participantes en el estudio, se determinó que la población fuesen mujeres de 15 años en adelante, con diferentes perfiles sociodemográficos y radicadas en San Cristóbal de Las Casas, las cuales manifestaran haber padecido violencia en algún momento de su vida y que además aceptaran ser entrevistadas. Se definió una muestra no probabilística de tipo intencional, producto de una selección 
de casos de acuerdo con los criterios establecidos por parte de quien investiga (Kazez, 2009), por ello, no se pretendió una representatividad estadística, sino más bien diversidad de perfiles para que a partir de ello se encontraran coincidencias y/o diferencias en las experiencias de mujeres con diversas trayectorias de vida. A las mujeres entrevistadas se les contactó por recomendación de personas conocidas que sabían de casos de mujeres que habían vivido episodios de violencia, se tuvieron acercamientos iniciales con ellas para presentarse, explicar las motivaciones del estudio y, en su caso, concertar las entrevistas con quienes aceptaran participar, de ello resultaron 14 entrevistas realizadas entre febrero y marzo de 2016.

Las entrevistas tuvieron sitio en tres tipos de lugares: seis fueron en los hogares de las mujeres, cuatro en cafeterías y/o restaurantes y cuatro en lugares públicos tales como parques y jardines. Al momento de ser entrevistadas, cuatro de las mujeres tenían edades de entre los 16 y 25 años, cinco entre 26 y 39, y cinco de 40 años en adelante, siendo la de mayor edad una mujer de 80 años. A todas las entrevistadas se les aseguró la confidencialidad y el anonimato de sus respuestas, por lo que sus nombres verdaderos fueron cambiados por otros ficticios.

Respecto a su estado civil, tres manifestaron ser solteras, tres vivir en unión libre, cuatro ser casadas, dos divorciadas y dos viudas. En cuanto a los hijos/as, tres dijeron no tener, 
cuatro dijeron que tenían 1 , una 2 , tres 3 y tres 4 . Sobre la procedencia de las entrevistadas, diez son de San Cristóbal de Las Casas, una de Comitán, una de Chanal, una de Bachajón y una de la ciudad de Veracruz. Con relación al máximo grado de estudios, tres no cuentan con instrucción escolar, cuatro cursaron hasta la primaria, una la preparatoria, cinco tienen estudios de licenciatura (una de ellas trunca) y una tiene doctorado. Respecto a sus ocupaciones, una se dedica a la arquitectura, una es empleada en una revista local, dos son empleadas domésticas, dos estudian y trabajan (una como asistente contable y otra como empleada de una Asociación Civil), una estudia la preparatoria, seis son trabajadoras del hogar sin remuneración (amas de casa) y una comerciante. A partir de una apreciación personal que consideró las características de su vivienda, el trabajo y actividades que realizan, así como los propios testimonios de las entrevistadas, es posible indicar que el nivel de ingresos de ocho de ellas es bajo, de cinco es medio y de una es alto.

Previo a la aplicación de las entrevistas se diseñó un guion de tipo semi-estructurado y se consideraron las recomendaciones de Fortunato Mallimaci y Verónica Giménez, quienes argumentan que:

Es importante tener en cuenta el aspecto diacrónico del relato de vida en el momento de elaborar la guía: las etapas centrales de la vida del entrevistado o la 
entrevistada deben ser consideradas. Es interesante que la infancia, la adolescencia, la adultez y la ancianidad figuren entre los puntos de la guía de una manera cronológica, y que, a su vez, sean cruzadas con las experiencias familiares, sociales, educativas, religiosas, laborales del entrevistado. (2006, p. 192)

En coincidencia con la postura anterior y retomando algunos de los elementos que utiliza Simone de Beauvoir para analizar la experiencia vivida de las mujeres, se fijaron como tópicos del guion de entrevista: la infancia, la adolescencia, el matrimonio y la maternidad (madresposa). Evidentemente, por la diversidad de perfiles de las entrevistadas y dado que algunas de ellas no han vivido alguna de esas etapas, no a todas se les preguntó lo mismo, por ejemplo, con las mujeres solteras no se preguntó respecto a su relación con el esposo. Después de aplicar las entrevistas, estas fueron transcritas junto con las notas de campo recabadas. Los tópicos establecidos en el guion conformaron árboles de categorías que permitieron que los testimonios fueran codificados y categorizados con ayuda del software de análisis cualitativo Nvivo. A partir de ello fue posible obtener la frecuencia y relevancia de los atributos que emergieron de cada categoría. 
RESULTADOS. CÓMO EXPERIMENTAN LA VIOLENCIA DE GÉNERO MUJERES DE SAN CRISTÓBAL DE LAS CASAS, CHIAPAS

\section{LAS EXPERIENCIAS EN LA INFANCIA}

De acuerdo con los testimonios, todas las mujeres entrevistadas comenzaron a experimentar algún tipo de violencia desde edades tempranas; recibían golpes, insultos o regaños. El maltrato ocurría con objetos como cinturones, palos, cueros o utensilios. El espacio de mayor ocurrencia del maltrato era la casa, todas indicaron que ahí era donde sucedía, y solo una de ellas indicó que también en la escuela. Respecto a quiénes eran las personas que ejercían violencia sobre ellas, eran, principalmente, padres y madres, pero también los abuelos en el caso de quienes vivían con ellos. Esto indica que son las personas responsables del cuidado de las hijas quienes mayoritariamente las maltrataban, de acuerdo con Sabrina Gómez “La razón del maltrato sería la reproducción transgeneracional de patrones de interacción padre-hijo, interacción que se caracteriza por el maltrato a los hijos" (Gómez, 1988, p. 151), es decir, padres y madres tratan a sus hijas/os de la forma en que también los trataron a ellos/as. Es interesante resaltar que el maltrato físico también da lugar al maltrato psicológico, las 
mujeres entrevistadas en sus experiencias de violencia aluden a emociones negativas; principalmente coraje, miedo, frustración y tristeza:

[Cuando le pegaban] iUy!, pues nada más llorar y llorar, siempre andaba yo triste pues. iAy!, es que no sé qué decir, porque no nos quería por ser niñas [su padre], pues no nos quería porque éramos niñas y pues quería un hijo varón y pues qué se podía hacer (Ernestina, 34 años, empleada doméstica).

En el caso de Ernestina y sus dos hermanas, estas comienzan a experimentar una minusvaloración por ser mujer, el padre quería un hijo, no hijas, y constantemente se los decía, es decir, la experiencia de género que comienzan a interiorizar, es aquella en el que las mujeres valen menos que los hombres. Aunado a lo anterior, su experiencia de género, también desde la infancia, se comienza a configurar con los mandatos sociales que les corresponden por ser niñas y niños, es una experiencia diferenciada y desigual a partir del sexo con el que nacen, hay expectativas y deberes sociales sobre ellas que son distintos a los de ellos y esto se traduce en un trato distinto y desigual.

Esos mandatos son claros cuando se trata de actividades que les corresponden a unos y otras: “Mi mamá nos enseña bien todo, a tortear, a lavar, a moler el maíz, hacer comida 
desde chicas, por eso ya sé bien pues" (Macaria, 34 años, empleada doméstica). Otro testimonio indica: "Pues a mí me enseñaron a hacer lo esencial, los quehaceres y todo eso" (Severa, 23 años, estudiante y asistente contable). En algunos casos, la experiencia de género se construye con el mandato superficial, les dicen lo que tienen qué hacer, pero en otros el sentido es más profundo porque además les indican para qué deben hacer eso: "Desde niñas tienen que hacerse mujeres para atender al hombre" (Elvira, 44 años, ama de casa). Otra de las entrevistadas manifestó: "Pues desde chicas hay que saber hacer los oficios de la casa para cuando tengamos marido ya sabemos hacer algo" (Ernestina, 34 años, empleada doméstica).

En los dos testimonios que se citan, desde la infancia, la experiencia de género se fue conformando a partir del sentido que se le da a lo que hacen "como mujeres" que son, es decir, se les enseña y se les exige hacer ciertas cosas porque la expectativa que sobre ellas recae es casarse, tener hijos/as y atender al marido. Desde la infancia se comienza a experimentar lo que implica ser mujer, en la interacción con el mundo social se empiezan a configurar disposiciones, hábitos y deberes que desde los discursos sociales emitidos por las instituciones, principalmente la familia en el caso de las entrevistadas, asignan significados al actuar de las mujeres. En esa experiencia de género, la violencia es un marcador importante, porque es el instrumento que se utiliza sobre ellas para indicarles cuál es el rol 
social que les corresponde y las consecuencias en caso de que lo trasgredan.

\section{LAS EXPERIENCIAS EN LA ADOLESCENCIA}

Una de las experiencias fundadas en una condición na-

tural, pero con significaciones culturales, es la del periodo menstrual. A algunas de las mujeres entrevistadas, principalmente a las de mayor edad, cuando lo tuvieron por primera vez les llegó con sorpresa y desconocimiento de qué ocurría, al no esperarlo, inicialmente tuvieron miedo, pero cuando las mujeres cercanas a ellas, ya sea la mamá, abuela o amigas les explicaron que a todas les pasaba, mencionaron que dejaron de tener miedo y lo vieron con naturalidad: "Tener con quién platicar esa experiencia pues te quita un poquito el miedo porque te das cuenta de que todas lo tenemos que vivir" (Catalina, 24 años, empleada en una revista local), aunque no por ello dejaba de ser incómodo, sobre todo para las mayores porque antaño no contaban con toallas femeninas.

Un testimonio representativo que alude al primer periodo menstrual como una experiencia importante de género, es el de una de las informantes a quien su abuela le dijo: "No hija, cuando estás así vas a ser mujer, ahorita estás como hombre, ya después ya viene tu menstruación, a los doce [o] trece dice, pero yo no, yo a los diez años" (Macaria, 34 años, empleada 
doméstica). Tal relato puede ser interpretado como un parteaguas en la experiencia femenina, pues si de niñas es posible que en algunos casos se les tuviera a las mujeres una que otra consideración similar a las que tenían los hombres, ello cambia por completo cuando "se convierten en mujeres", cuando dejan de ser "como hombres".

En la juventud, las mujeres entrevistadas experimentaron sus primeros acercamientos amorosos con el sexo opuesto, las edades de ello oscilaban entre los quince y veinte años. En esta etapa las mujeres no dejaron de experimentar violencia, de hecho, se reconfiguró o acentuó en lo relacionado con su sexualidad:

No cambió mucho porque conforme íbamos creciendo pues nos cuidaban más, de que no jugáramos con los niños porque era peligroso, porque nos podía pasar algo o nos podían faltar el respeto y pues no podíamos andar solas a altas horas de la noche, y si salíamos pues ya con nuestros papás, pero sí, a esa edad ya nos cuidaban un poco más, bueno en mi caso pues siempre me cuidaron hasta que me casé. (Carmen, 46 años, ama de casa)

Es muy representativo el testimonio anterior que indica que la cuidaron hasta que se casó, porque en ese marco, más que cuidado, puede interpretarse como vigilancia, en la cual cambia el custodio pero no la custodiada. Otro de los testimonios 
coincide con lo citado por Raquel Gutiérrez (2010), cuando refiere que el cuidado que recae sobre las mujeres cuando inician la juventud, es un cuidado distinto al infantil; una de las entrevistadas indica: "Ya me cuidaban más ya, ya no como niña otra vez, porque ya si salía yo en la calle ya decían que iba yo a encontrar novio o me iba yo a ir por ahí" (Elvira, 44 años, ama de casa).

Se refleja una preocupación constante por lo que pueden hacer las mujeres con los hombres: “[su papá] no nos permitía ni salir, ni nada, porque si no... nos dice que ya estamos buscando hombres" (Ernestina, 34 años, empleada doméstica). Lo que hay detrás es una intención de inhibir el ejercicio de la sexualidad por la posibilidad de que queden embarazadas fuera de la norma social, religiosa y civil, es decir, la preocupación es que tengan relaciones sexuales y queden embarazadas sin estar casadas y con ello "deshonren a la familia", ello produce miedo en las mujeres, lo que mina su autonomía y su autoestima. De hecho, cuando el temor se convierte en realidad, es decir, cuando efectivamente las mujeres se embarazan fuera de la norma, ello las expone también a la posibilidad de que experimenten violencia: “Lo que sí, era el miedo de decirle a mi papá de que estaba yo embarazada, y de hecho yo busqué un lugar así público para decirle" (Manuela, 30 años, ama de casa).

Quedar embarazada o irse con el novio sin permiso, es interpretado como una ofensa a la familia, lo cual genera con- 
secuencias que generalmente son castigos o maltratos expresados en manifestaciones de violencia "si te dejas tocar ya vas a tener hijo me decían ya más me cuidaban ya, sí pues, incluso cuando ya decidí huirme me buscaron y me regresaron a cuerazos otra vez" (Elvira, 44 años, ama de casa). Lo que debe ser una mujer cuando es joven lo tenían muy claro: decente, recatada, mostrar respeto a sus padres, no acercarse a los hombres $y$, por supuesto, no "salir embarazada", porque si no se cumple con todo ello, el riesgo es ser violentada, principalmente de manera física, aunque los estragos no solo afectan lo físico, sino también lo emocional y psicológico.

\section{LAS EXPERIENCIAS COMO MADRESPOSA}

Para Marcela Lagarde: "ser madresposa es un cautiverio construido en torno a dos definiciones esenciales positivas de las mujeres: su sexualidad procreadora, y su relación de dependencia vital de los otros por medio de la maternidad, la filialidad y la conyugalidad" (Lagarde, 2005, pp. 38-39). Tomando ello en consideración, en la experiencia de las mujeres resaltan al menos dos de estos elementos: la relación con sus hijos y la relación con su esposo. Respecto a cómo experimentan la violencia en ambas relaciones, en la primera, en algunos casos son ellas quienes perpetran la violencia y en la segunda, mayoritariamente son ellas las violentadas. 
En cuanto a cómo se llevan con sus esposos, varias manifestaron que desde pequeñas les "enseñaron" cómo debían relacionarse con ellos, principalmente las entrevistadas de mayor edad: "Tenés que saber tu quehacer, y así me aconsejaba mi mamá, y hacer lo que dice tu marido, obedeces para que no se enoje" (Felicia, 80 años, ama de casa), "Por eso decía pue' mi mamá que tenemos que hacer el trabajito porque cuando se casa uno, no va a venir atrás nuestra mamá, y para que no se enoje el marido tenemos que saber ya solas cómo mantener pue' el esposo" (Jovita, 58 años, comerciante). Incluso en esas enseñanzas se les hacía énfasis en que si había golpes, en determinadas circunstancias, estos podrían ser justificados por el incumplimiento de sus deberes:

Mi mamá decía que yo me portara bien, que yo le obedeciera todo mi marido y, que para que no hubiera ningún problema, que yo lo atendiera bien y todo eso, para que no se enojara y no me fuera a pegar porque si eso pasaba era porque algo estaba mal hecho y si me pegaba pues era con justa razón. (Elvira, 44 años, ama de casa)

Cuando a las entrevistadas se les cuestionó respecto a cuáles consideraban que eran los motivos por los que había conflictos con sus parejas, independientemente de si derivaban en violencia o no, las respuestas más recurrentes fueron: porque 
el marido toma (alcohol), porque desobedecían al marido, por falta de confianza, porque el marido tiene problemas en el trabajo, por infidelidades del marido, por problemas con los hijos/as, por falta de comunicación, por problemas económicos. Tal como en la infancia y en la juventud, las mujeres casadas manifestaron que en el matrimonio también hay distinciones entre lo que puede y debe hacer un hombre (esposo) y una mujer (esposa), así como la sensación que tienen ellas de menor libertad que ellos:

Bueno, no lo hace seguido pero así de que él sí puede llegar a veces ya medio tomado y a altas horas de la noche, yo no lo podría hacer, porque no sé, siento que... como ya tengo una niña, siento que ya no tengo esa libertad de poder llegar a esas horas icon quién la dejo y todo eso? Y porque además él es hombre. (Manuela, 30 años, ama de casa)

Las enseñanzas en la infancia son expectativas y obligaciones con las que se tiene que cumplir de adulta; cocinar, atender al marido y cuidar a los hijos/as son algunas de ellas, cuando esto no se hace, se vigila, cuestiona y sanciona. Otro de los testimonios indica: "Es la madre quien tiene la responsabilidad de las mujeres, de lo bueno o malo que les pueda pasar, las responsables son ellas de la educación de las hijas" (Camelia, 36 años, ama de casa). Socialmente se considera que 
es una obligación casi exclusivamente de las madres "educar bien a los/as hijos/as", y enfáticamente tratándose de niñas y adolescentes; es decir, es responsabilidad de la madre que las hijas sean decentes, propias, recatadas, y si "salen embarazadas" seguramente es porque "la mamá la descuidó". Estos testimonios son muy interesantes porque dan pie no solo para hablar de cómo se relacionan las mujeres entre sí; sino también para inferir cómo se relacionan con sus hijos/as, porque como se mencionó antes, su experiencia de género también está permeada por este tipo de relaciones.

En ese sentido, la mayoría de las entrevistadas resaltó que procuran tener con sus hijos/as relaciones de confianza, apoyo, comunicación, libertad sana y responsable; no obstante, a la vez manifestaron que a veces es conveniente recurrir a regaños y golpes leves; solo una entrevistada manifestó que era importante educar con mano dura. A partir de estos testimonios, se puede interpretar que para algunas mujeres del estudio, la violencia es adecuada, siempre y cuando esta no sea grave, aunque algunas más mencionaron que no les pegan a sus hijos/as, las que menos recurren a la violencia en su mayoría son las de mayor grado de estudios. Ello nos habla de que si bien las mujeres son "guardianas del orden del género" (Lagarde, 1996b), en determinados contextos pueden ser factores para que se reconfigure el orden social en su conjunto y no solo el de género. 
Mientras unos aspectos se reconfiguran, tales como que algunas mujeres no educan a sus hijos/as con golpes, otros aspectos, quizás los de mayor arraigo social y cultural, se siguen reproduciendo, por ejemplo, el considerar que determinadas actividades les corresponden a las mujeres por ser mujeres. En las experiencias de género, experiencias de violencia y no, van conformando los significados del ser mujer; es por eso que en la parte final de las entrevistas se les preguntaba justamente por el significado que para ellas tenía ser mujer; un aspecto que resalta es que la mayoría lo relacionó con los roles tradicionales de género, salvo una, la de mayor grado académico y mejor situación económica, quien mostró matices de lo tradicional combinado con otros aspectos relativos al trabajo fuera de casa, pero en los demás casos, ser mujer significa: algo bonito, trabajar, pensar en los hijos/as, ser higiénica, arreglarse, ser motivadora, comprensiva, escuchar y entender a los hijos/ as, vestirse bien pero decente, ser comunicativa, pensar en sí misma y en su familia, tener confianza en sí misma, ser positiva, tener valores, quererse mucho.

Es así como la experiencia de género en las mujeres que son madres y esposas está marcada por el tipo de relación que establecen con sus maridos y sus hijos/as. Con los primeros, se refleja una continuidad que se puede ubicar en las enseñanzas, principalmente de sus madres, es decir, se relacionan con sus maridos de la forma en que les enseñaron que debían hacerlo (obedecerlo y atenderlo), cuando esto no ocurre o cuando el 
marido es alcohólico, infiel o tiene problemas en el trabajo, con los hijos/as o económicos, es cuando se presentan los conflictos y la violencia. Respecto a cómo se relacionan las mujeres con sus hijos/as, en algunos casos se puede ver una ligera reconfiguración de la relación, ya no basada en violencia física dura, sino en la procuración de la confianza y la comunicación, según lo expresado por las entrevistadas.

\section{SITUACIÓN VITAL Y CONDICIÓN DE GÉNERO}

Se puede decir que como género, la condición de las mujeres es de subordinación con respecto a los hombres, eso en lo general, pero de acuerdo con la situación vital de cada mujer, esta subordinación puede variar en grado e intensidad. Por ejemplo, la situación actual de Karina, debido a su profesión, nivel de ingresos, edad, etcétera, es de no subordinación o de menos subordinación que la que podría tener Jacinta, quien es menor de edad, no es profesionista, depende económicamente de sus padres, etcétera. La situación de ambas no es fija, ha cambiado y seguirá cambiando con los años; si Jacinta se convierte en profesionista o comienza a tener ingresos, su situación vital puede transitar a una de menor subordinación. No obstante y lamentablemente, ambas por ser mujeres se encuentran en condición de vulnerabilidad social y, estadísticamente es probable que en algún 
momento sean víctimas de algún tipo de violencia, pues según datos levantados en 2016 por la ENDIREH, en nuestro país el $66.1 \%$ de las mujeres han sufrido al menos un incidente de violencia emocional, económica, física, sexual o discriminación a lo largo de su vida en al menos un ámbito y ejercida por cualquier agresor (INEGI, 2017). Esa probabilidad es una condición de género femenino.

Un aspecto que alude a la situación vital, es en el que coinciden Yolanda y Jovita, cuando refieren a su soledad, no es posible afirmar que sea un aspecto no compartido por las demás mujeres, no obstante, solo ellas dos lo refirieron. Para el caso de Yolanda, su ex novio aprovechó que "no tenía a nadie" para humillarla y adueñarse de su vida. En el caso de Jovita, por presión de sus hijos no pudo "rehacer su vida" después de que su esposo murió y ahora que sus hijos se han ido, "estar sola" la hace sentirse triste. En un sentido un poco diferente pero relacionado, es el caso de Ernestina, a quien de joven su patrón la intentó violar porque pensó que "estaba sola". En estos casos se asume que "estar sola" es una desventaja, consideran que les falta algo o alguien, se asumen como personas carenciales, y eso también marca sus experiencias de género.

Una situación que es coincidente entre Ernestina y María, es la relacionada con su práctica religiosa, para ambas su experiencia de género está marcada por mandatos religiosos y familiares en los que el perdón al maltratador y acatar la vo- 
luntad de Dios es importante. En el caso de Carmen, una situación que únicamente ella manifestó, fue referente a sus problemas con la suegra y cuñadas; para ella era importante demostrarles que no era una mala mujer, esposa y madre por trabajar y contribuir al ingreso familiar.

En cuanto a la situación de Karina, también se encontraron aspectos relevantes porque aun siendo de familia acomodada, ello no significó que de niña y adolescente no fuese controlada o vigilada, tampoco que no hubiera desigualdades respecto a sus hermanos o en el trato de su papá con ella por ser mujer, es decir, algunos aspectos de la forma en que la trataron de niña bien puede coincidir con la mayoría de las entrevistadas; pero su situación cambió y se diferenció de las demás al momento de irse a estudiar fuera del país y con el tiempo convertirse en una profesionista reconocida, situación que no es compartida por otras mujeres del estudio y que también marca su experiencia de género. Claro está que no cualquier mujer tiene acceso a una oportunidad como la que ella tuvo, pero eso también es reflejo de una situación vital particular.

La condición de género de las mujeres estudiadas, como ya se comentó, tiene dos ejes principales, aunque podrían no ser los únicos, la sexualidad y la relación con el poder (Lagarde, 2005). Si atendemos esos dos ejes en los relatos de las entrevistadas, se aprecia como condición de género que la relación con el poder es una relación de sujeción con respecto a 
otros miembros de la familia, principalmente los padres, aunque también con las mamás (que también están sujetas a sus esposos) y con hermanos varones. Una consecuencia de esa relación de sujeción, es el miedo que la mayoría manifestó que les provocaban sus padres, no hay mayor reflejo de poder que el miedo que causa el poderoso.

Independientemente de la edad que ahora tienen, el origen social o el lugar en el que nacieron, la condición de género que permea la experiencia de las mujeres entrevistadas es de frustraciones, restricciones y prohibiciones, prácticamente todas coinciden en que tenían menos libertad que los hombres de su familia, no podían decidir ni opinar sobre sí mismas y había un excesivo control sobre ellas y sus acciones, un ejemplo de ello es que no podían salir si no iban acompañadas.

También como condición de género, se pueden enmarcar las cargas diferenciadas de trabajo que recaen sobre las mujeres desde que son pequeñas, pues están obligadas a hacer labores que correspondan con lo que se considera apropiado para ellas, tienen que aprender de sus mamás y ayudarles en los quehaceres domésticos, no pueden por ningún motivo hacer cosas que socialmente sean consideradas como cosas de hombres. Aún de adultas, los trabajos que desempeñan, salvo el caso de Karina, son trabajos "propios de mujeres" que tienen que ver principalmente con labores domésticas.

Respecto al eje de la sexualidad, este no se puede separar del eje del poder, las entrevistadas manifestaban que había una 
estricta vigilancia sobre ellas y sus cuerpos, lo cual se manifestaba en las prohibiciones para salir, jugar o incluso hablar con varones; lo que hay de trasfondo, que no es explicitado por los padres pero está implícito, es el control que se desea ejercer sobre el sexo y la sexualidad de las mujeres; es decir, por lo que se preocupan los familiares es que las mujeres no tengan relaciones sexuales antes del matrimonio, porque sería "una desgracia", "una deshonra" para la familia y, principalmente, para los padres porque religiosa y socialmente no está bien visto ni permitido que las mujeres expresen o satisfagan sus deseos sexuales, mucho menos antes del matrimonio.

A todas las entrevistadas las prepararon desde pequeñas para casarse, y eso implica llegar preparadas sabiendo cocinar, lavar, planchar y todo lo que tenga que ver con las labores domésticas y el cuidado de los hijos/as; hay cosas de hombres y cosas de mujeres, futuros deseables para ellos y para ellas y lo que se desea para ellas es casarse, tener hijos, ser buenas esposas y ser buenas madres, eso constituye a una buena mujer. En cambio, de los hombres se espera que sean padres fuertes, valientes, que tomen las decisiones, activos sexualmente, que sepan trabajar (fuera de casa), que tomen alcohol, entre otros mandatos. Eso es una condición de género y eso marca la experiencia vivida.

Otros aspectos que no necesariamente cabrían en alguno de los dos ejes, aunque podrían estar relacionados y que fueron compartidos por la mayoría, son el agradecimiento, la pena 
y la palabra. Independientemente de los malos tratos que han recibido y recibieron en su infancia, prácticamente todas están agradecidas con sus padres y madres, dicen que por ellos son lo que son, e incluso los disculpan porque "también a ellos los educaron así" o porque "no sabían lo que hacían". Sobre la pena, resulta entendible que a la mayoría les resultaba penoso hablar sobre los temas que se les preguntaban, quizás porque la violencia, la menstruación y la sexualidad aún son temas tabús que se consideran personales y que no se deben hacer públicos, sin embargo, el riesgo de no hablar sobre ello, es que sigan considerándose asuntos individuales y no se les dé la relevancia social que en realidad tienen.

También es interesante que la mayoría expresara su agradecimiento por ser escuchadas, la entrevista que se les hizo fue una oportunidad para que exteriorizaran emociones contenidas o coartadas, se sintieron bien al hablar, al hacer uso de la palabra y expresar cosas que les hieren, las lastiman o les parecen injustas. Entonces, se puede decir que se identificó la necesidad de ser escuchadas como una condición de género entre las mujeres del estudio, aspecto sugerente si consideramos que etimológicamente la palabra "persona" se compone de dos elementos per y sonare, el primero significa "con intensidad" y el segundo "hacerse escuchar" (Martínez, 2005), es decir, para que las y los individuos adquiramos la calidad de personas debemos hacernos escuchar con intensidad, y lo que sucedió en la interlocución que se tuvo con las entrevis- 
tadas cada que expresaban tristeza, llanto, enojo y otras emociones, fue justamente que estaban haciéndose escuchar, sus historias estaban siendo escuchadas y pasaban de individuos a personas, de objetos sobre los que se ejercía maltrato a sujetos que expresaban sus emociones.

\section{CONSIDERACIONES FINALES}

Las experiencias tienen marcas de género, cuando se asigna un género al nacer también se asigna la forma en que se habrá de experimentar el mundo, lo que se viva y la forma en que se viva dependerá de si se es niño o niña. Las experiencias de las mujeres están atravesadas por la situación vital de cada una y por la condición de género; quienes padecen malos tratos, experimentan en momentos clave de su vida, tales como la infancia, juventud, matrimonio, maternidad, y de manera violenta, lo que significa ser mujer. En cada una de esas etapas, se aprende y se aprehende, cooperando o por medios violentos, qué se espera y cómo "debe de ser" una niña, una jovencita decente y una buena madresposa, y cómo es que "no" deben ejercer la sexualidad.

Aunque las experiencias de violencia de cada una de las mujeres entrevistadas fueron distintas, hay elementos similares en etapas importantes de su vida que corresponden a la condición de género. Es decir, aunque sus orígenes y estratos sociales son distintos, expresaron que en la infancia, adoles- 
cencia y aún en la adultez, existió control, vigilancia y otros tipos de violencia sobre sus cuerpos y sus acciones. La mayoría coincidió en que de niñas sus padres hacían distinción entre ellas y sus hermanos hombres, demostrándoles que ellas eran menos libres que ellos.

En la infancia se les insistió mucho en el tipo de actividades que les correspondía hacer y aprender "por ser niñas", cuando no cumplían con esas expectativas y obligaciones, la violencia sobre sus cuerpos y sus emociones se convertía en una herramienta para hacerlas entender cuál era su lugar en el mundo social en tanto mujeres que eran. Si bien durante su niñez se les limitaba su comportamiento y se les restringía la interacción con los niños, esas limitaciones se incrementaron en la medida en que llegaron a la adolescencia, ahí el cuidado y control infantil se convirtió en vigilancia juvenil, era aún más enfática la prohibición de relacionarse con hombres, se les exigía ser decentes y "darse a respetar"; cuando no cumplían con esos mandatos, el maltrato y la violencia se utilizaban como medios para castigar las transgresiones al "deber ser"; en esa etapa, a los padres les preocupa y les ocupa que las hijas no queden embarazadas. En la etapa de madresposas, la sensación de menos libertad sigue presente, ya no están los padres para exigirles lo que deben hacer, pero sí están los maridos para violentarlas física o moralmente en caso de que no cumplan con su papel de mujeres. 
Es así que las experiencias de violencia de las mujeres están permeadas por sus experiencias de género, que a su vez, están relacionadas con su situación vital y su condición de género. En los testimonios de las entrevistadas, se alude a significados, representaciones, y autorepresentaciones que conforman el ser mujer; todo ello alimentado por discursos sociales e instituciones como la familia, que producen y reproducen hombres y mujeres con determinadas características que son el caldo de cultivo para la violencia, es decir, si se educa a las mujeres para que sean sumisas, obedientes, dependientes, recatadas, etc., ello afectará su autoestima, su autonomía, su cuerpo y sus emociones, y si a la par se educan hombres arrojados, impetuosos, forzados a que todo el tiempo deben estar demostrando su masculinidad y su valentía, resulta una mala combinación. Caso distinto es el de la entrevistada Karina, quien se considera autosuficiente y con autoestima para no depender de nadie y lograr lo que se proponga, justo porque a través de la educación escolar y vivencias distintas, logró darle otro significado a su experiencia de género. De ahí que fomentar la mayor preparación académica de las mujeres sea una buena forma de empoderarlas, aunque esto no signifique que en automático estarán exentas de violencia.

Un aspecto interesante y que es importante resaltar, es que aunque las experiencias de género estén arraigadas en la sociedad, estas no son inmutables, pues a partir del testimonio de las entrevistadas se pudo constatar que la mayoría está 
buscando nuevas formas de relacionarse con sus hijos/as, formas que a decir de ellas no son violentas, si bien eso no implica que no reproduzcan y les inculquen los roles de género tradicionales, al menos no se los están imponiendo de manera coercitiva, lo que les brinda a los hijos/as una mayor posibilidad de autodeterminación.

\section{Bibliografía}

Beauvolr, S. (1981). El Segundo Sexo. Buenos Aires: Siglo veinte.

CAstañeda, M. (2012). Etnografía feminista. En N. Blazquez, F. Flores y M. Ríos (Coords.), Investigación feminista. Epistemología, metodología y representaciones sociales (pp. 217-238). México, D. F.: UNAM.

Colectivo Feminista Mercedes Olivera y Bustamante A. C. (COfemO). (2016). Estudio sobre la violencia a las mujeres en San Cristóbal de Las Casas. http://www.nodo50.org/pchiapas/chiapas/documentos/ femicidio.htm

Diario Oficial de la Federación (DOF). (2007). Ley General de Acceso de las Mujeres a una Vida Libre de Violencia. http://www.dof.gob.mx/ nota_detalle.php?codigo $=4961209 \&$ fecha $=01 / 02 / 2007$

DíAz, R. (1997). La vivencia en circulación. Una introducción a la antropología de la experiencia. Alteridades, (13). 5-15.

Gómez, S. (1988). Maltrato infantil: Un problema multifacético. Revista Latinoamericana de Psicología, 20(2). 149-161.

GutiéRREZ, R. (2010). Desandar el laberinto. Introspección en la feminidad contemporánea. México: Pez en el árbol. 
INEGI. (2016). Principales resultados de la Encuesta Intercensal 2015: Chiapas.

Aguascalientes: INEGI.

INEGI. (2017). Resultados de la Encuesta Nacional sobre la Dinámica de las Relaciones en los Hogares (ENDIREH) 2016. http://www.inegi.org.mx/ saladeprensa/boletines/2017/endireh/endireh2017_08.pdf.

KAZEZ, R. (2009). Los estudios de caso y el problema de la selección de la muestra. Revista Subjetividad y procesos cognitivos, (13). 71-89.

LAGARDE, M. (1996a). Género y feminismo. Desarrollo humano y democracia. España: horas y HORAS.

LARGADE, M. (1996b). La multidimensionalidad de la categoría género y del feminismo. En M. L. González Marín, Metodología para los estudios de género (pp. 48-71). México: UNAM.

LAGARDE, M. (2005). Los cautiverios de las mujeres: madresposas, monjas, putas, presas y locas. México, D. F.: UNAM.

LAMAS, M. (1996). La antropología feminista y la categoría "género". En M. Lamas (Comp.), El género. La construcción cultural de la diferencia sexual (pp. 97-125). México: PUEG / Miguel Ángel Porrúa.

LAMUS, D. (2015). Guía para la investigación cualitativa y de género. Colombia: Universidad del Atlántico.

Lauretis, T. (1994). La tecnología del género. En H. Buarque de Hollanda (Coord.), Tendencias e impasses: o feminismo como critica da cultura (pp. 206-242). Rio de Janeiro: Rocco.

MALLIMACI, F. Y GIMÉnEZ, V. (2006). Historia de vida y métodos biográficos. En I. Vasilachis (Coord.), Estrategias de investigación cualitativa (pp. 175-212). Barcelona: Gedisa Editorial. 
Martín, A. (2008). Antropología del género. Culturas, mitos y estereotipos sexuales. Madrid: Ediciones Cátedra.

Martínez, V. (2005). Podemos hacer las paces. Reflexiones éticas tras el 11-S y el 11- M. España: Descleé De Brouwer.

Morales, E., SÁnchez, H. y ZÚÑIGA, E. (2008). Violencia familiar en hogares sancristobalenses. En M. Olivera (Coord.), Violencia feminicida en Chiapas. Razones visibles y ocultas de nuestras luchas, resistencias y rebeldías (pp. 45-83). San Cristóbal de Las Casas: UNICACH.

MuÑoz, P. (2011). Violencias interseccionales. Debates feministas y Marcos Teóricos en el tema de Pobreza y Violencia contra las mujeres en Latinoamérica. Tegucigalpa: CAWN.

Observatorio Feminista contra la Violencia a las Mujeres de Chiapas (OFVMCH). (2018). Reportes estadísticos de agosto, septiembre, octubre, noviembre y diciembre 2017. http://observatoriofeministadechiapas.blogspot.com Organización de Estados Americanos (OEA). (1994). Convención de Belémdo Pará.http://www.unicef.org/argentina/spanish/ar_insumos_Convencion Belem.pdf

ONU (1993). Declaración sobre la eliminación de la violencia contra la mujer. http://www.ohchr.org/SP/Professionallnterest/Pages/ ViolenceAgainstWomen.aspx

ONu (1996). Informe de la Cuarta Conferencia Mundial sobre la Mujer. http://www.un.org/womenwatch/daw/beijing/pdf/ Beijing\%20full\%20report\%20S.pdf

RUBIN, G. (1986). El tráfico de mujeres: notas sobre la "economía política" del sexo. Nueva Antropología, 8(30), 95-145.

SAUTU, R. (2005). Todo es teoría. Objetivos y métodos de investigación. 


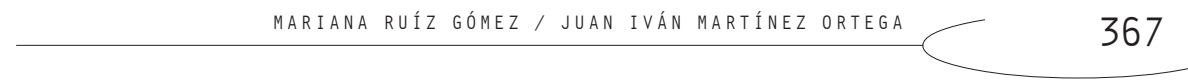

Buenos Aires: Lumiere.

ScotT, J. (1996). El género: una categoría útil para el análisis histórico. En M. Lamas (Coord.), El género: la construcción cultural de la diferencia sexual (pp. 265-302). México, D. F.: Miguel Ángel Porrúa.

Secretariado Ejecutivo del Sistema Nacional de Seguridad Pública (SESNSP). (2018). Información delictiva y de emergencias con perspectiva de género. http://secretariadoejecutivo.gob.mx/docs/pdfs/nuevametodologia/Info_delict_persp_genero_DIC2017.pdf

VALles, M. (1997). Técnicas cualitativas de investigación social. México: Síntesis. 